\title{
Mannose-binding lectin is present in the infected airway: a possible pulmonary defence mechanism
}

\author{
K J Fidler, ${ }^{1} \mathrm{~T}$ N Hilliard, ${ }^{2,3}$ A Bush, ${ }^{2,3} \mathrm{M}$ Johnson, ${ }^{4} \mathrm{D}$ M Geddes, ${ }^{5} \mathrm{M}$ W Turner, ${ }^{4}$ \\ E W F W Alton, ${ }^{2} \mathrm{~N}$ J Klein, ${ }^{1} \mathrm{~J}$ C Davies ${ }^{2,3}$
}

${ }^{1}$ Infectious Diseases and Microbiology Unit, Institute of Child Health, London, UK;

${ }^{2}$ Department of Gene Therapy Imperial College, London, UK;

${ }^{3}$ Paediatric Respiratory Medicine, Royal Brompton Hospital, London, UK:

${ }^{4}$ Immunobiology Unit, Institute of Child Health, London, UK;

${ }^{5}$ Thoracic Medicine, Royal

Brompton Hospital, London, UK

Correspondence to:

Dr J C Davies, Department of Gene Therapy, Imperial College, London SW3 6LR, UK;

j.c.davies@imperial.ac.uk

These data have been published in abstract form (Pediatr Pulmonol 2005;:28:241).

Received 4 April 2008 Accepted 23 September 2008 Published Online First

6 November 2008

\begin{abstract}
Background: Mannose-binding lectin (MBL) deficiency has been associated with infections of the respiratory tract and with increased disease severity in cystic fibrosis (CF). The mechanism is uncertain, and could relate either to systemic or local effects. The aim of this study was to determine, in a large cohort of children, whether MBL is present on the airway surface in health or disease.
\end{abstract}

Methods: Bronchoalveolar lavage (BAL) fluid from children with and without respiratory infection (some with underlying disease) was analysed for MBL and neutrophil elastase (NE). Levels were compared between groups, and correlations were examined with local and systemic inflammatory markers, infective organisms and load.

Results: 85 children were recruited to the study. MBL was absent in the lavage of all 7 children without lung infection but present in $62 \%(8 / 13)$ of those with acute pneumonia/pneumonitis, 23\% (5/22) with recurrent respiratory tract infections, $17 \%(1 / 6)$ with primary ciliary dyskinesia and $8 \%(3 / 37)$ with CF $(p<0.01)$. Children with acute pneumonia/pneumonitis had significantly higher levels than those in the other groups. There was no relationship with organisms cultured or systemic markers of inflammation, although in the group with detectable $M B L$ in the BAL fluid, the levels correlated positively with levels of NE.

Conclusions: MBL is undetectable in the non-infected airway but is present in a significant number of samples from children with lung infection. The levels found in the BAL fluid could be physiologically active and the protein may therefore be playing a role in host defence.

The respiratory tract is continually challenged by infective, allergenic and pollutant agents against which it possesses an array of defence mechanisms. The innate immune system comprises structural and cellular components and proteins such as defensins and the hydrophilic surfactant proteins (SP) A and D. The latter proteins-members of the collectin family-bind surface carbohydrates on pathogens, enhancing phagocytosis and modifying the inflammatory response..$^{1-3}$ Transgenic mouse models have confirmed their importance in local host defence. ${ }^{45}$ Another collectin, mannose-binding lectin $(\mathrm{MBL})$, is similar both structurally and functionally to the hydrophilic surfactant proteins. $\mathrm{MBL}$ is a liver-derived serum protein that binds to mannose and $\mathrm{N}$-acetyl glucosamine residues commonly found on micro-organisms. ${ }^{6}$

Human deficiency of MBL is predominantly caused by point mutations within exon 1 of the MBL-2 gene at codons 52(D), 54(B) or 57(C), resulting in amino acid substitutions which compromise assembly of functional oligomers.
Heterozygous individuals have reduced serum concentrations of MBL, while functional multimeric protein is almost absent from the serum of homozygotes and compound heterozygotes. In addition to the exon 1 mutations, there are three major polymorphisms in the promoter region of the MBL gene and one of these variants $(X / Y)$ also profoundly influences levels of the protein. More than one-third of the population will have haplotypes associated with reduced MBL levels, with very low levels expected in $12 \%{ }^{67}$ Numerous studies have now shown that individuals with MBL deficiency are more susceptible to a variety of infections and are predisposed to increased severity of both infection and inflammation. ${ }^{8-14}$ MBLdeficient polymorphisms have been reported in association with respiratory infections in childhood, increased pneumococcal infections in adults and more severe lung disease in adults with cystic fibrosis. ${ }^{15-22}$ However, almost no work has been conducted on MBL levels at the airway surface and it is unknown whether MBL functions locally within the airway or exerts these effects systemically. One previous study reported that MBL was absent in the bronchoalveolar lavage (BAL) fluid of healthy mice, but detectable after intratracheal instillation of influenza A virus. ${ }^{23} \mathrm{~A}$ single small study on 10 human subjects has reported similarly that MBL could be found in BAL fluid in the presence of respiratory disease but not in healthy controls. ${ }^{24}$ Based on its known mechanisms of action and functional similarities with the surfactant proteins $\mathrm{A}$ and $\mathrm{D}$, it seems likely that $\mathrm{MBL}$ which reaches the airway surface would be capable of contributing to host defence.

The aim of this study was to determine if MBL is present in BAL fluid in health or disease in children with and without lung disease.

\section{METHODS}

\section{Patient population}

Children undergoing BAL were divided prospectively into the following six groups:

- Group 1: Acute pneumonia or pneumonitis (PP, $n=13)$ : these children were all ventilated on the paediatric intensive care unit (PICU) at Great Ormond Street Hospital, where a diagnosis of pneumonia or pneumonitis was made on the basis of radiological changes with a consistent history. The children underwent diagnostic non-bronchoscopic BAL.

- Group 2: Cystic fibrosis (CF, $\mathrm{n}=37$ ): these children had been diagnosed by sweat test and/ or genotyping and were undergoing bronchoscopy and BAL either as a routine investigation 
at the time of diagnosis, for lack of response to antibiotic treatment or for research purposes at the time of a general anaesthetic for a surgical procedure.

- Group 3: Primary ciliary dyskinesia (PCD, $n=6)$ : this had been diagnosed on nasal brushing samples and these children were undergoing elective bronchoscopy for microbiological surveillance.

- Group 4: Recurrent lower respiratory tract infections (RLRTIs, $\mathrm{n}=22$ ): these children had had at least two LRTIs over the course of their life and were undergoing elective bronchoscopy during a period of clinical stability (a minimum of 4 months after resolution of an acute illness) as part of a respiratory investigation.

- Group 5: Acute non-infective conditions (eg, postoperative, trauma, $n=4)$ : these ventilated children on the PICU were undergoing BAL for failure to extubate and/or to exclude infection. A non-infective diagnosis such as veno-occlusive disease or failure to extubate due to central CNS trauma was made in all cases. In addition, they all had negative microscopy for organisms, negative bacterial, fungal and virological cultures and negative PCRs for a wide panel of respiratory viruses. These patients therefore acted as part of a "control" group.

- Group 6: Upper airway problems (UA, $n=3)$ : these patients underwent bronchoscopy for the investigation of upper airway structural problems. Ethical approval had previously been obtained to perform BAL on these patients who also formed an important "control" group. In none were any adverse effects of the BAL seen.

For most analyses of results these groups were analysed independently but, for the purposes of discussion, patients from group 1 are referred to as having acute disease, groups 2-4 as having chronic disease and groups 5 and 6 as the "controls".

Patient demographic and microbiological/virological data were obtained from the routine laboratories at each institution and/or from the referring hospital.

\section{Bronchoalveolar lavage collection and sample processing}

BAL was performed with 1-3 aliquots of $1 \mathrm{ml} / \mathrm{kg}$ (maximum $30 \mathrm{ml}$ ) sterile $0.9 \%$ saline in either the right middle lobe (bronchoscopic) or aimed at a region of radiographic change (non-bronchoscopic). Fifteen of 17 patients on the PICU had a non-bronchoscopic BAL performed by a senior physiotherapist. The remaining two patients on the PICU and all the patients at the Royal Brompton Hospital had a bronchoscopic BAL performed by a paediatric respiratory consultant. BAL fluid aliquots were pooled and, provided sufficient was available for the required clinical investigations, a sample was retained for research. Samples were immediately placed on ice and spun at $400 \mathrm{~g}$ for $10 \mathrm{~min}$ at $4^{\circ} \mathrm{C}$. The supernatant was removed and stored in aliquots at $-80^{\circ} \mathrm{C}$ until analysis.

\section{Serum MBL levels}

Blood samples (1-2 $\mathrm{ml}$ ) were spun, separated and the serum stored in aliquots at $-80^{\circ} \mathrm{C}$ until analysed. In 15 of the 17 of the patients in the PICU and 18 of 33 patients with CF, $1-2 \mathrm{ml}$ of whole blood in EDTA was also taken for MBL genotyping. Genotyping was performed for the exon 1 mutations and the $\mathrm{X} / \mathrm{Y}$ promoter polymorphisms, from which haplotypes were constructed as described below. ${ }^{14}$

\section{MBL-2 haplotyping}

The three $M B L-2$ structural gene mutations $\mathrm{B}, \mathrm{C}$ and $\mathrm{D}$ are in linkage disequilibrium with the promoter region polymorphism
$\mathrm{X} / \mathrm{Y}$ so that Y only occurs with each of the mutations. To date, no exceptions to these associations have been reported and, accordingly, the data from heteroduplexing procedures were combined to give haplotypes comprising one of the three structural gene mutations $(O)$ or wild type (A) together with the $\mathrm{X} / \mathrm{Y}$ promoter polymorphism.

\section{Influence of protease inhibitors on levels of endogenous and spiked MBL in BAL fluid}

To determine whether protease inhibition following collection of BAL fluid was necessary to prevent potential MBL degradation, the supernatant from 25 patients was divided and treated with or without a cocktail of protease inhibitors (Complete Mini, Roche Diagnostics, Mannheim, Germany). These patients represented all of the disease groups. In addition, eight of these samples-representing two patients each from the PP, CF, PCD and RTI groups - were spiked with $10 \mathrm{ng} / \mathrm{ml}$ purified $\mathrm{MBL}^{25}$ and the effect of the same protease inhibitor cocktail on yield was measured.

\section{MBL protein levels measured by ELISA}

$\mathrm{MBL}$ levels in BAL fluid and serum were determined by a symmetrical sandwich ELISA (Antibody Shop, Copenhagen, Denmark). Serum was diluted to $1 / 50-1 / 200$, whereas BAL fluid was used neat or at $1 / 2$ dilution, with results being corrected for the dilution factor. Optical densities on the standard curve from 0.1 to 1.7 (equating to approximate MBL levels of 4-6500 ng/ $\mathrm{ml}$ ) were accepted. Results higher than $6500 \mathrm{ng} / \mathrm{ml}$ were repeated with further dilutions as appropriate. Levels below $4 \mathrm{ng} / \mathrm{ml}$ were counted as zero. Samples were anonymised ensuring "blinding" to patient diagnoses until the results were analysed.

\section{Neutrophil elastase levels}

Neutrophil elastase (NE) was measured in BAL fluid with a colorimetric assay based on NE cleaving nitroanilide from a substrate (N-methoxysuccinyl-ala-ala-pro-val-p-nitroanilide) according to the manufacturer's instructions (Sigma Aldrich, St Louis, USA). $10 \mu \mathrm{l}$ sample volumes were used and levels were expressed as milliunits $(\mathrm{mU}) / \mathrm{ml} ; 1 \mathrm{mU}$ activity was the lowest standard tested and the range of the assay was $20-5000 \mathrm{mU} / \mathrm{ml}$, so any value below $20 \mathrm{mU} / \mathrm{ml}$ was taken as zero.

\section{Statistical analysis}

Differences between groups were assessed using Kruskal-Wallis, Mann-Whitney, $\chi^{2}$, Fisher exact or Wilcoxon signed rank tests as appropriate. Spearman and Pearson correlations were performed where appropriate. Dunns post hoc test was used to compare disease groups after multiple group analysis. As the

Table 1 Demographic details of patient groups in BAL study

\begin{tabular}{lll}
\hline $\begin{array}{l}\text { Diagnostic group } \\
\text { (total } \mathbf{n}=\mathbf{8 5})\end{array}$ & $\begin{array}{l}\text { M:F ratio } \\
(\% \text { male) }\end{array}$ & $\begin{array}{l}\text { Median (range) } \\
\text { age (years) }\end{array}$ \\
\hline $\begin{array}{l}\text { Acute pneumonia/pneumonitis } \\
\text { ( } \mathrm{n}=13)\end{array}$ & $9: 4(69)$ & $4.0(0.1-16.3)$ \\
$\begin{array}{l}\text { Cystic fibrosis }(\mathrm{n}=37) \\
\text { PCD }(\mathrm{n}=6)\end{array}$ & $13: 24(35)$ & $7.7(0.3-16.8)$ \\
RLRTI $(\mathrm{n}=22)$ & $2: 4(33)$ & $9.5(5.7-14.8)$ \\
$\begin{array}{l}\text { Acute non-infective "other" } \\
\text { ( } \mathrm{n}=4)\end{array}$ & $11: 11(50)$ & $5.3(0.9-15.2)$ \\
Upper airway $(\mathrm{n}=3)$ & $2: 2(50)$ & $8.0(0.2-15.1)$ \\
$\mathrm{p}$ Value & $3: 0(100)$ & $7.2(5.8-7.5)$ \\
\hline
\end{tabular}

PCD, primary ciliary dyskinesia; RLRTI, recurrent lower respiratory tract infections. 
majority of the data were non-parametrically distributed, the results are presented as median (range). Data from the PI and spiking experiments were normally distributed and were analysed with paired $t$ tests and expressed as mean (SD). Analysis was performed using GraphPad Prism Version 3.0 for Windows (GraphPad Software, San Diego, California, USA) and SPSS for Windows V.9.

\section{RESULTS}

\section{Demographic characteristics of study patients}

Eighty-five children were recruited to the main part of the study analysing BAL fluid. The demographic characteristics and diagnoses of the children are shown in table 1. Seventeen patients had urgent BAL performed while ventilated on the PICU. The remaining $68 \mathrm{BAL}$ examinations were performed electively. Controls included three children with upper airway obstruction and four with acute non-infective "other" diagnoses (one with severe asthma, one with pulmonary venoocclusive disease and two children who failed extubation, one after a severe head injury and one with a non-pulmonary
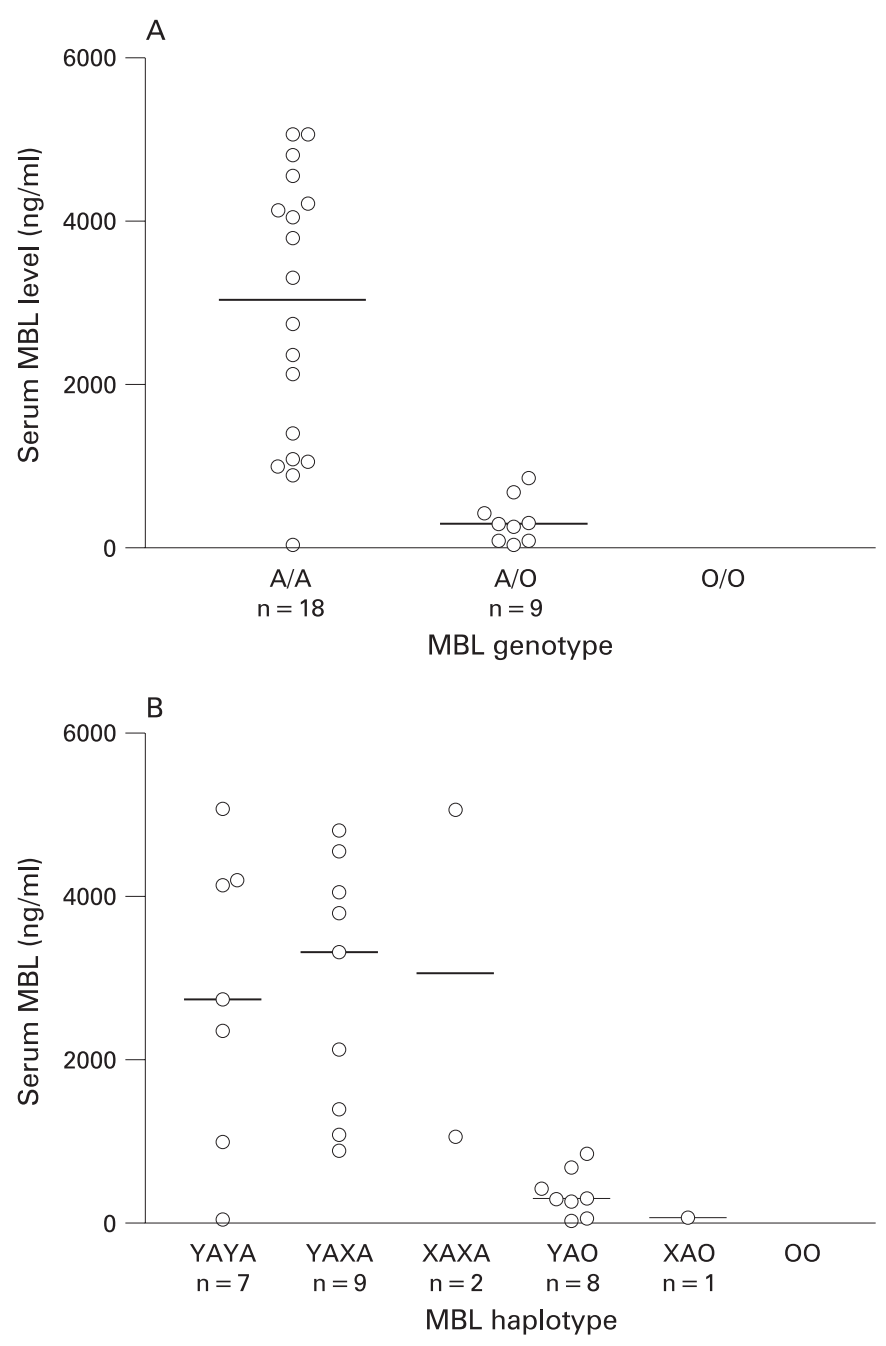

Figure 1 Correlation of serum levels of mannose-binding lectin (MBL) with MBL haplotypes. Median MBL levels were significantly different between $(A) M B L$ genotypes $(p=0.002)$ and $(B)$ haplotypes $(p=0.006)$ in 27 patients in whom both were available. An outlier in the very small XAXA group $(n=2)$ resulted in median MBL levels being higher than is usually seen. A, wild type; 0 , exon 1 mutation; $Y$, high expressing promoter; $\mathrm{X}$, low expressing promoter. malignancy). Forty of the 85 children (47\%) were boys and the median age was 5.7 years (range 1 month-16.8 years). There were no significant differences in the mean ages $(p=0.25)$ or gender proportions $(p=0.13)$ between disease groups.

\section{MBL genotype and serum levels}

Thirty-three patients had MBL genotypes performed, including all those with acute pneumonia/pneumonitis and about half of those with CF or an acute non-infective illness. In these groups, approximately two-thirds had a wild type genotype (A/A) and one-third were heterozygous for a mutation $(\mathrm{A} / \mathrm{O})$; none of them had the $\mathrm{O} / \mathrm{O}$ genotype (percentage of patients with the $\mathrm{A} /$ A genotype: PP $69 \%$, CF $72 \%$, acute other $(n=2) 50 \%)$. In this group, the observed distribution of both genotypes and haplotypes was not significantly different from that expected
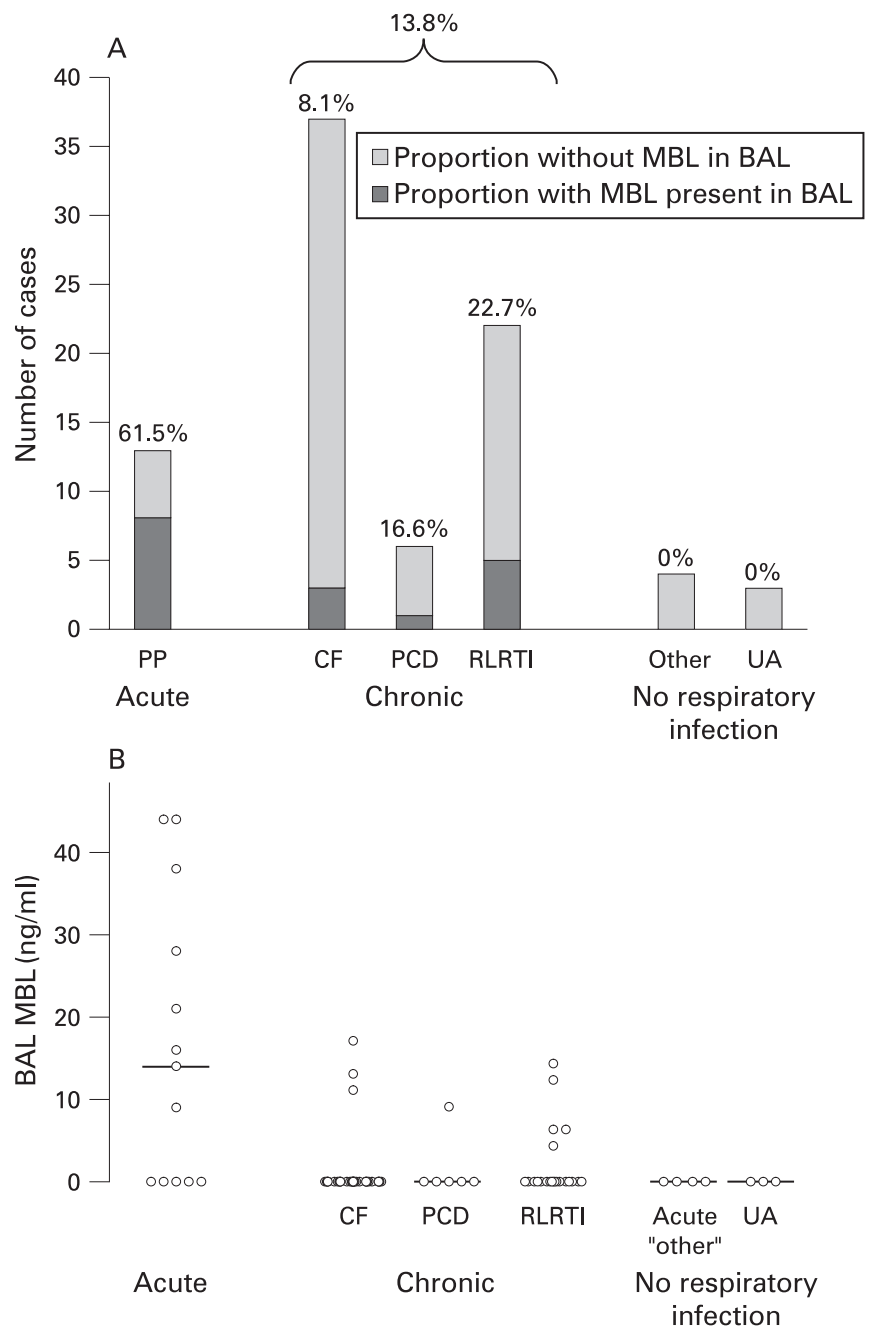

Figure 2 (A) Proportions of patients with mannose-binding lectin $(\mathrm{MBL})$ in bronchoalveolar lavage (BAL) fluid. The proportion of patients with $M B L$ detectable in BAL fluid differed significantly in the different disease groups $(p<0.01)$, the highest proportion being observed in the acute pneumonia/pneumonitis (PP) group. No MBL was present in any of the seven patients with no respiratory disease. (B) Relationship of BAL fluid levels of MBL to disease group. Median levels of MBL were significantly higher in the PP group than in the other groups $(p<0.001$; $p<0.001$ vs chronic respiratory disease, $p<0.05$ vs no respiratory infection, Kruskal-Wallis test). CF, cystic fibrosis; PCD, primary ciliary dyskinesia; RLRTI, recurrent lower respiratory tract infection; UA, upper airway. 
in UK published series. ${ }^{26}$ In 78 children serum was available for determination of $\mathrm{MBL}$ levels. In the 27 who were also genotyped, median serum MBL levels were significantly different between both genotypes and haplotypes (fig 1), as previously reported by ourselves and others. ${ }^{14}{ }^{18} 20$ Levels were not age- or sex-dependent.

\section{Influence of protease inhibitors on levels of endogenous and spiked MBL in BAL fluid}

Of the 25 samples treated with and without protease inhibitors, seven samples had no MBL detected either with or without the cocktail. In the rest of the group, paired analysis revealed no significant difference in the levels with and without protease inhibitors $(p=0.4)$. No sample had MBL detected only in the presence of protease inhibitors. Eight samples were spiked with $10 \mathrm{ng} / \mathrm{ml}$ purified MBL and the yield and effect of protease inhibitors studied. MBL was detected in all spiked samples, with a mean (SD) recovery for the group of $72(20) \%$; for the two CF samples, recovery rates were $79 \%$ and $54 \%$. As in the unspiked samples, protease inhibitors had no significant effect on final MBL concentrations detected $(p=0.4)$. In view of this, all results reported hereafter are from samples which had not been treated with protease inhibitors.

\section{MBL levels in BAL fluid}

MBL was detected in 17 BAL fluid samples overall $(20 \%)$ and could be found in a proportion from each of the groups with pulmonary disease, but in no child without lower respiratory disease (fig 2A). The acute pneumonia/pneumonitis group had a significantly greater proportion of patients with MBL present in the BAL fluid $(p<0.002)$ and significantly higher median levels than in any of the other disease groups (fig $2 B, p<0.001$ ). Not all the patients with $\mathrm{MBL}$ detected in their BAL fluid possessed the MBL genotype AA; in fact, the two patients with the highest BAL fluid levels of MBL had the genotype YA/O. A significant negative correlation was seen between serum and BAL fluid levels of MBL (fig 3, $\mathrm{p}=0.002$ ).

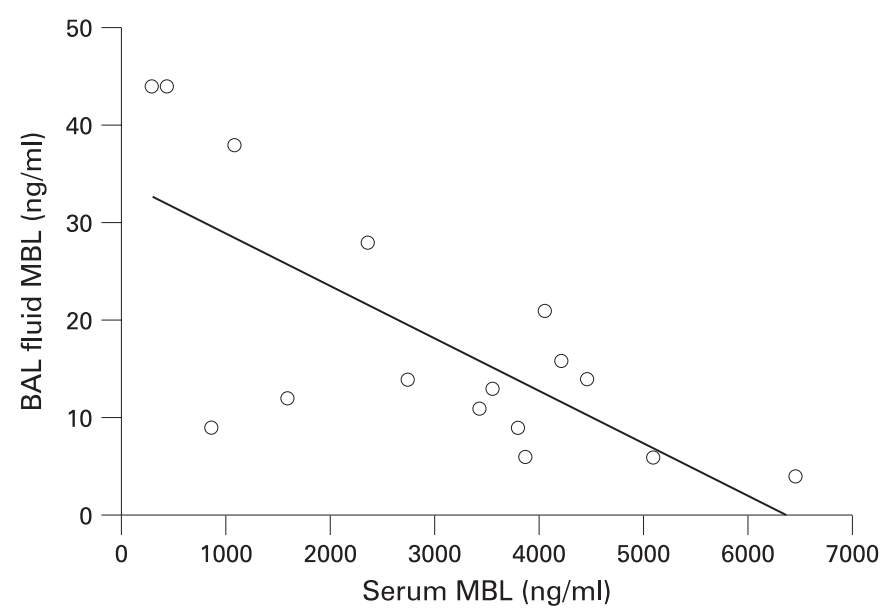

Figure 3 Relationship between mannose-binding lectin (MBL) levels in serum and bronchoalveolar lavage (BAL) fluid. In 16/17 children with $\mathrm{MBL}$ present in BAL fluid, serum samples were also available for determination of $\mathrm{MBL}$ levels. There was a significant negative correlation between serum and BAL fluid levels of MBL (Pearson $r=-0.72$, $\mathrm{p}=0.002$ ).

\section{Correlation with inflammatory markers}

Levels of airway inflammation as determined by NE differed significantly between groups (fig 4; $\mathrm{p}<0.001$ ), with the highest median levels occurring in the PP and CF groups. For the cohort as a whole, BAL fluid levels of MBL did not correlate significantly with $\mathrm{NE}$, although in the subgroup with detectable $\operatorname{MBL}(n=17)$ there was a modest positive correlation $(r=0.52$, $\mathrm{p}<0.05$ ). In contrast, no correlations were observed between BAL fluid levels of MBL and systemic inflammatory markers including C-reactive protein, total leucocyte count or neutrophil counts.

\section{Microbiology}

Overall, an organism was cultured from 30 of the 85 children (35\%): PP group 6/13; CF group 12/37; PCD group 3/6; RLRTI group 9/22; acute "other" 0/4; and UA group 0/3. Importantly, many children had received antimicrobial treatment before relevant bacterial and virological cultures were obtained, so this detection rate was probably falsely low. Twenty-nine strains of pathogenic bacteria were isolated from BAL fluid from $26(30 \%)$ children: Pseudomonas aeruginosa $\mathrm{n}=7$; Haemophilus influenzae $\mathrm{n}=7$; Streptococcus pneumoniae $\mathrm{n}=6$; Staphylococcus aureus $\mathrm{n}=6$; Stenotrophomonas maltophilia $\mathrm{n}=2$; Branhamella catarrhalis $\mathrm{n}=1$ ). Two children in the acute PP group had viruses isolated from the BAL fluid (Epstein-Barr virus and influenza A). Two further children in the PP group had organisms isolated from other sites, one with varicella pneumonitis and disseminated disease (isolated from the skin) and the other with group A streptococcal pneumonia and toxic shock (isolated from blood culture). None of the children assigned to the "acute noninfective" or upper airway groups had positive cultures. Owing to small numbers in some of the groups, the differences in the proportion of patients from each group yielding a positive culture did not reach significance $(p=0.36)$, although children with airway disease were significantly more likely than those in the control groups to have a positive culture $(38 \%$ vs $0 \%$, $p=0.041)$. Those in whom bacteria and/or viruses were isolated had neither an increased frequency of MBL in their BAL fluid nor higher median levels.

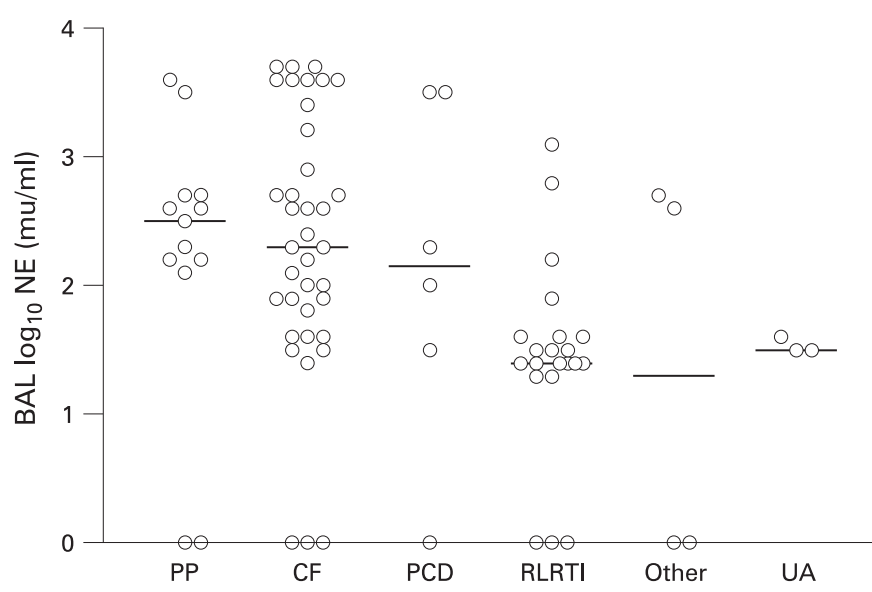

Figure 4 Bronchoalveolar lavage (BAL) fluid levels of neutrophil elastase (NE) across clinical groups. NE levels were significantly higher in the acute pneumonia/pneumonitis (PP), cystic fibrosis (CF) and primary ciliary dyskinesia (PCD) groups than in the group with recurrent lower respiratory tract infections (RLRTI) and those with acute "other" and upper airway (UA) infections (ie, controls; $p=0.001$ ). 


\section{DISCUSSION}

This is the first large human study to attempt to measure $\mathrm{MBL}$ at the airway surface and shows that, while the protein is absent in normal health, it is present in moderate to high levels in a variety of lung disease states in children. We therefore hypothesise that some of the links reported by ourselves and others between MBL deficiency and lung disease might relate to the fact that MBL is able to play a role in local host defence. Children with acute pneumonia/pneumonitis were most likely to have MBL detected in the BAL fluid and they had the highest concentrations. Intermediate levels were observed in more chronic disease states and the protein was not detectable in any child from our control groups. When present, concentrations of $\mathrm{MBL}$ correlated with those of $\mathrm{NE}$, a marker of local inflammation, although not with culturable pathogens or systemic inflammation.

This study has several limitations, partly because of the opportunistic acquisition of the BAL samples in these children. The numbers of patients in the control groups were small and they had a variety of different conditions. These small numbers reduced power for some of the statistical comparisons. However, obtaining lavage samples from healthy paediatric lungs is difficult, both logistically and ethically, and this is a common limitation of such studies. In addition, some patients in the control groups had raised levels of NE. This could have related, for example, to ventilator-associated airway damage or other processes, but they were clearly not a pure "healthy airway" control group. The inclusion of other inflammatory markers could have increased our understanding of such processes and improved the quality of the study. Another limitation is the variable timing of acquisition of the BAL sample after the onset of the illness or commencement of treatment. $\mathrm{MBL}$ levels are likely to vary over time in acute conditions and possibly also in more chronic conditions in response to exacerbations or stability of disease. Owing to the relatively invasive nature of BAL, it is unlikely that clinical studies with sufficient power will be conducted in a longitudinal fashion, although animal models could be used to examine such variability more closely. Finally, the levels detected in the patients with acute PP in this study were similar to the median level of $19 \mathrm{ng} / \mathrm{ml}$ reported previously in adults with acute pneumonia, ${ }^{24}$ but BAL produces samples with an unknown and probably extremely high dilution factor. ${ }^{27}$ The procedure was conducted in as standardised a fashion as possible, but levels reported will clearly not be those present on the airway surface in vivo. This might in part explain the greater correlation with BAL fluid levels of NE (from the same sample and thus with the same dilution factor) than blood markers, although this may also reflect true differences in inflammatory response in the two body compartments.

Despite these limitations, these data clearly demonstrate that $\mathrm{MBL}$ does reach the diseased airway. We did not design this study to address whether MBL is functional in the lung, and future studies should examine this. Although we found $\mathrm{MBL}$ in the BAL fluid of patients with and without structural $M B L-2$ mutations, it remains unclear whether the oligomeric structure of the MBL-and hence the function-is affected, as it is in the serum. ${ }^{78}$ Further work with non-reduced gradient gel electrophoresis of MBL from BAL fluid would be needed to determine this. However, our data do suggest that the levels present would be sufficient for function: it has been estimated that MBL levels required for complement activation are likely to be in the region of $300-400 \mathrm{ng} / \mathrm{ml}^{29}{ }^{30}$ whereas the levels that were detected in these BAL fluid samples reached a maximum of $44 \mathrm{ng} / \mathrm{ml}$. Based on reports using markers to calculate the dilution of epithelial lining fluid by instilled saline during $\mathrm{BAL},{ }^{31}$ and taking into account the $70 \%$ yield of $\mathrm{MBL}$ added to the samples during spiking experiments, levels in the epithelial lining fluid are likely to be 1-2 logs higher than this, well within the range for function. Experiments to examine $\mathrm{MBL}$ binding to respiratory pathogens found in these BAL fluid samples may tease out further mechanisms by which $\mathrm{MBL}$ may be operating in the lung. ${ }^{32}{ }^{33}$ On binding, MBL activates the complement system in an antibody-independent manner (the lectin pathway) via MBL-associated serine protease (MASP-2) which cleaves first $\mathrm{C} 4$ and then C2 to form the C3 convertase C4b2a. This enzyme is able to generate significant amounts of opsonic C3b fragments which coat micro-organisms for phagocytosis. There is also evidence of direct interaction of MBL with phagocytic cells to promote phagocytosis and modify cellular activation. ${ }^{32-34}$ However, in addition to a direct role in clearance of microbes, there is increasing evidence in support of an immunomodulatory effect of MBL. ${ }^{34}{ }^{35}$ It has previously been considered whether this may account for the link between MBL deficiency and CF disease severity, ${ }^{18-21}$ as it has been shown that $\mathrm{MBL}$ binds very poorly to the major CF respiratory pathogen $P$ aeruginosa. ${ }^{36}$

This study was not designed to explore the mechanism by which MBL reaches the airway surface; suggestions would include passive leak through a damaged epithelium, active secretion or local production. The correlation with NE would support passive leak, as this enzyme has previously been shown to lead to a breakdown of intercellular junctions ${ }^{37}$ and epithelial disruption, ${ }^{38}$ both of which would be likely to increase levels of serum proteins in the BAL fluid. However, although long thought to be a liver-derived protein, MBL-A mRNA has recently been detected in the murine lung, ${ }^{39}$ so that local production cannot be completely ruled out. Determination of expression levels in respiratory epithelial cells or local inflammatory cells in the context of disease and health could aid further understanding of this. To try and investigate the possible mechanism further, BAL fluid levels of MBL were correlated with serum levels of MBL and, unexpectedly, there was a significant inverse relationship between them. In fact, the two patients with the highest MBL levels in BAL fluid (44 and $44 \mathrm{ng} / \mathrm{ml}$ ) were two children with acute pneumonia/pneumonitis who had the lowest serum MBL levels (294 and $422 \mathrm{ng}$ / $\mathrm{ml}$ ). If the level of $\mathrm{MBL}$ in BAL fluid merely reflects passive leakage from high serum levels, then a positive correlation would have been expected. As the converse was seen, active secretion could be involved as well or, if passive leakage is the mechanism, it must also be related to disease severity and damage to the integrity of the epithelium. One possibility is that more severe disease may be seen in those with the lowest serum levels of $\mathrm{MBL}$, thus accounting for the inverse relationship seen here. Unfortunately, the numbers in this study are too small to correlate MBL levels in BAL fluid and serum with paediatric disease severity scores.

Having demonstrated MBL in the diseased airway, one could perhaps question why it was not found more consistently; the inconsistency was particularly marked for patients in the chronic/subacute disease groups. This could be explained either by increased breakdown of the protein or reduced leakage through the airway wall. With regard to the former, proteolytic degradation of structurally similar proteins (SP-A and SP-D) has been reported in patients with chronic airway diseases, ${ }^{40}{ }^{41}$ and Garred et al reported rapid disappearance of $\mathrm{MBL}$ in the serum when it was exposed to CF sputum. ${ }^{18}$ However, while NE is 
clearly not the only proteolytic enzyme in the inflamed airway, it is widely regarded as key and the positive correlation between this enzyme and MBL in the BAL fluid in our study would appear to go against this hypothesis. Alternatively, variable leakage onto the airway surface could be a feature of chronic diseases which vary widely in severity and the variable time points during cycles of stability and exacerbation at which the samples were taken. We do not have prospectively collected data which would allow us to analyse this accurately; such an analysis would be valuable and will be included in future studies.

In conclusion, $\mathrm{MBL}-\mathrm{a}$ protein similar in structure and function to the collectins more conventionally associated with the lung (SP-A and SP-D) - may be contributing to lung host defence by acting locally at the airway surface.

Acknowledgements: The authors thank Drs R Dinwiddie, A Jaffe, I Balfour-Lynn and M Rosenthal and physiotherapists at Great Ormond Street Hospital for help with bronchoscopy and lavage, and the patients and their parents for participating in the study.

Funding: This work was supported by the following foundations: The Wellcome TrustTraining Fellowship (KJF) and Senior Research Fellowship (EWFWA); Cystic Fibrosis Trust (JCD). Work in the Institute of Child Health is also supported by The Wellcome Trust, EU Grant Contract No. OLRT-CT-2001-01039 and by Action Research. Research at the Institute of Child Health and Great Ormond Street Hospital for Children National Health Service (NHS) Trust benefits from research and development funding received from the UK NHS Executive.

Competing interests: MWT and NJK act as scientific consultants for Natlmmune, a Danish company exploring the therapeutic potential of mannose-binding lectin.

Ethics approval: Local research ethics committee approval was obtained from Great Ormond Street Hospital and The Royal Brompton, Harefield and NHLI Trust. All parents or carers gave informed consent and assent was obtained from children where appropriate.

\section{REFERENCES}

1. van Iwaarden F, Welmers B, Verhoef J, et al. Pulmonary surfactant protein A enhances the host-defense mechanism of rat alveolar macrophages. Am J Respir Cell Mol Biol 1990;2:91-8.

2. Kuan SF, Persson A, Parghi D, et al. Lectin-mediated interactions of surfactant protein D with alveolar macrophages. Am J Respir Cell Mol Biol 1994;10:430-6.

3. Malhotra R, Haurum JS, Thiel S, et al. Binding of human collectins (SP-A and MBP) to influenza virus. Biochem J 1994;304:455-61.

4. Li G, Siddiqui J, Hendry M, et al. Surfactant protein-A-deficient mice display an exaggerated early inflammatory response to a beta-resistant strain of influenza $A$ virus. Am J Respir Cell Mol Biol 2002;26:277-82.

5. Atochina EN, Gow AJ, Beck JM, et al. Delayed clearance of pneumocystis carinii infection, increased inflammation, and altered nitric oxide metabolism in lungs of surfactant protein-D knockout mice. J Infect Dis 2004:189:1528-39.

6. Turner MW. Mannose binding lectin: the pluripotent molecule of the innate immune system. Immunol Today 1996;17:532-40.

7. Lipscombe RJ, Sumiya M, Summerfield JA, et al. Distinct physicochemical characteristics of human mannose binding protein expressed by individuals of differing genotype. Immunology 1995;85:660-7.

8. Summerfield JA, Ryder S, Sumiya M, et al. Mannose-binding protein gene mutations associated with unusual and severe infections in adults. Lancet 1995;345:886-9

9. Summerfield JA, Sumiya M, Levin M, et al. Association of mutations in mannose binding protein gene with childhood infection in consecutive hospital series. BMJ 1997:314:1229-32.

10. Hibberd ML, Sumiya M, Summerfield JA, et al, the Meningococcal Research Group. Association of variants of the gene for mannose-binding lectin with susceptibility to meningococcal diseases. Lancet 1999;353:1049-53.

11. Neth 0, Hann I, Turner MW, et al. Deficiency of mannose-binding lectin and burden of infection in children with malignancy: a prospective study. Lancet 2001:358:614-8.

12. Peterslund NA, Koch C, Jensenius JC, et al. Association between deficiency of mannose-binding lectin and severe infections after chemotherapy. Lancet 2001;358:598-9.

13. Garred P, Strom J, Quist L, et al. Association of mannose-binding lectin polymorphisms with sepsis and fatal outcome in patients with systemic inflammatory response syndrome. J Infect Dis 2003;188:1394-403.
14. Fidler KJ, Wilson P, Davies JC, et al. Increased incidence and severity of the systemic inflammatory response syndrome in patients deficient in mannose-binding lectin. Intensive Care Med 2004;30:1438-45

15. Roy S, Knox K, Segal S, et al. MBL genotype and risk of invasive pneumococcal disease: a case-control study. Lancet 2002;359:1569-73.

16. Koch A, Melbye M, Sorensen $\mathrm{P}$, et al. Acute respiratory tract infections and mannosebinding lectin insufficiency during early childhood. JAMA 2001;285:1316-21.

17. Cedzynski M, Szemraj J, Swierzko AS, et al. Mannan-binding lectin insufficiency in children with recurrent infections of the respiratory system. Clin Exp Immunol 2004;136:304-11

18. Garred P, Pressler T, Madsen $\mathrm{HO}$, et al. Association of mannose-binding lectin gene heterogeneity with severity of lung disease and survival in cystic fibrosis. J Clin Invest 1999; 104:431-7.

19. Gabolde M, Guilloud-Bataille M, Feingold J, et al. Association of variant alleles of mannose binding lectin with severity of pulmonary disease in cystic fibrosis: cohort study. BMJ 1999:319:1166-7.

20. Davies JC, Turner MW, Klein N. Impaired pulmonary status in cystic fibrosis adults with two mutated MBL-2 alleles. Eur Respir J 2004;24:798-804.

21. Carlsson M, Sjoholm AG, Eriksson L, et al. Deficiency of the mannan-binding lectin pathway of complement and poor outcome in cystic fibrosis: bacterial colonization may be decisive for a relationship. Clin Exp Immunol 2005;139:306-13.

22. Buranawuti K, Boyle MP, Cheng $\mathbf{S}$, et al. Variants in mannose-binding lectin and tumour necrosis factor alpha affect survival in cystic fibrosis. J Med Genet 2007;44:209-14.

23. Reading PC, Morey LS, Crouch EC, et al. Collectin-mediated antiviral host defense of the lung: evidence from influenza virus infection of mice. J Virol 1997:71:8204-12.

24. Gomi K, Tokue $Y$, Kobayashi $T$, et al. Mannose-binding lectin gene polymorphism is a modulating factor in repeated respiratory infections. Chest 2004;126:95-9.

25. Devyatyarova-Johnson M, Rees $\mathbf{I H}$, Robertson BD, et al. The lipopolysaccharide structures of Salmonella enterica serovar typhimurium and Neisseria gonorrhoeae determine the attachment of human mannose-binding lectin to intact organisms. Infect Immun 2000;68:3894-9.

26. Mead R, Jack D, Pembrey M, Tyfield L, Turner M, the ALSPAC Study Team. Mannose-binding lectin alleles in a prospectively recruited UK population. Lancet 1997;349:1669-70.

27. Rennard SI, Basset G, Lecossier D, et al. Estimation of volume of epithelial lining fluid recovered by lavage using urea as marker of dilution. J Appl Physiol 1986;60:532-8.

28. Dean MM, Heatley S, Minchinton RM. Heteroligomeric forms of codon 54 mannose binding lectin (MBL) in circulation demonstrate reduced in vitro function. Mol Immunol 2005:43:950-61.

29. Valdimarsson H, Stefansson M, Vikingdottir T, et al. Reconstitution of opsonizing activity by infusion of mannan-binding lectin (MBL) to MBL deficient humans. Scand J Immunol 1998:48:116-23.

30. Neth 0, Jack DL, Dodds AW, et al. Mannose-binding lectin binds to a range of clinically relevant microorganisms and promotes complement deposition. Infect Immun 2000;68:688-93.

31. Restrick LJ, Sampson AP, Piper PJ, et al. Inulin as a marker of dilution of bronchoalveolar lavage in asthmatic and normal subjects. Am J Respir Crit Care Med 1995; 151:1211-7.

32. Kuhlman M, Joiner K, Ezekowitz RA. The human mannose-binding protein functions as an opsonin. J Exp Med 1989;169:1733-45.

33. Tenner AJ, Robinson SL, Ezekowitz RAB. Mannose-binding protein (MBP) enhances mononuclear phagocyte function via a receptor that contains the $126,000 \mathrm{~m}(\mathrm{r})$ component of the C1q receptor. Immunity 1995;3:485-93.

34. Jack DL, Read RC, Tenner AJ, et al. Mannose-binding lectin regulates the inflammatory response of human professional phagocytes to Neisseria meningitidis serogroup B. J Infect Dis 2001;184:1152-62.

35. Sprong T, Jack DL, Klein NJ, et al. Mannose binding lectin enhances IL-1beta and IL 10 induction by non-lipopolysaccharide (LPS) components of Neisseria meningitidis. Cytokine 2004;28:59-66.

36. Davies J, Neth 0, Alton E, et al. Differential binding of mannose-binding lectin to respiratory pathogens in cystic fibrosis. Lancet 2000;355:1885-6.

37. Azghani A0. Pseudomonas aeruginosa and epithelial permeability: role of virulence factors elastase and exotoxin A. Am J Respir Cell Mol Biol 1996;15:132-40.

38. Amitani R, Wilson R, Rutman A, et al. Effects of human neutrophil elastase and Pseudomonas aeruginosa proteinases on human respiratory epithelium. Am J Respir Cell Mol Biol 1991;4:26-32.

39. Uemura K, Saka M, Nakagawa T, et al. L-MBP is expressed in epithelial cells of mouse small intestine. J Immunol 2002;169:6945-50.

40. Griese M, Essl R, Schmidt R, et al. Pulmonary surfactant, lung function, and endobronchial inflammation in cystic fibrosis. Am J Respir Crit Care Med 2004:170:1000-5

41. Rubio F, Cooley J, Accurso FJ, et al. Linkage of neutrophil serine proteases and decreased surfactant protein-A (SP-A) levels in inflammatory lung disease. Thorax 2004:59:318-23. 